\title{
Fluorine important element in new drugs synthesis: Review Study
}

\author{
Ahmed A. Mahmood ${ }^{1}$, Mohammed A.Al-Iraqi ${ }^{2}$, Faris T. Abachi ${ }^{1}$ \\ 1 Department of Pharmaceutical Chemistry, College of Pharmacy, \\ 2 Department of Chemistry, College of Science, University of Mosul, Mosul, Iraq. farisabachi@yahoo.com
}

\section{$\underline{\text { Received } \quad \text { Accepted }}$ \\ 31.3.2018 28.5.2018}

\begin{abstract}
Objective:To evaluate the role of fluorine atom in modern drug synthesis.

Methods: Different types of fluorinated were prepared, antimicrobials, antivirals, FNSAIDs, peptides and protein synthesis.

Results: Recent developments and future prospects of fluorine in medicinal chemistry and chemical biology. The extraordinary potential of fluorine - containing biologically relevant molecules in antimicrobial or antivirial agents, or peptide or protein chemistry, medicinal chemistry, chemical biology, pharmacology, and drug discovery as well as diagnostic and therapeutic applications, was recognized by researchers who are not in the traditional fluorine chemistry field, and thus the new wave of fluorine chemistry has been rapidly expanding its biomedical frontiers.

Conclusion: This review how to list of fluorinated drugs( Antimicrobial agents , anticancer agents, Antiviral agents, and study their physicochemical properties of fluorine drugs.
\end{abstract}

Keywords: Fluorine drugs, antimicrobial, anticancer, therapeutic applications.

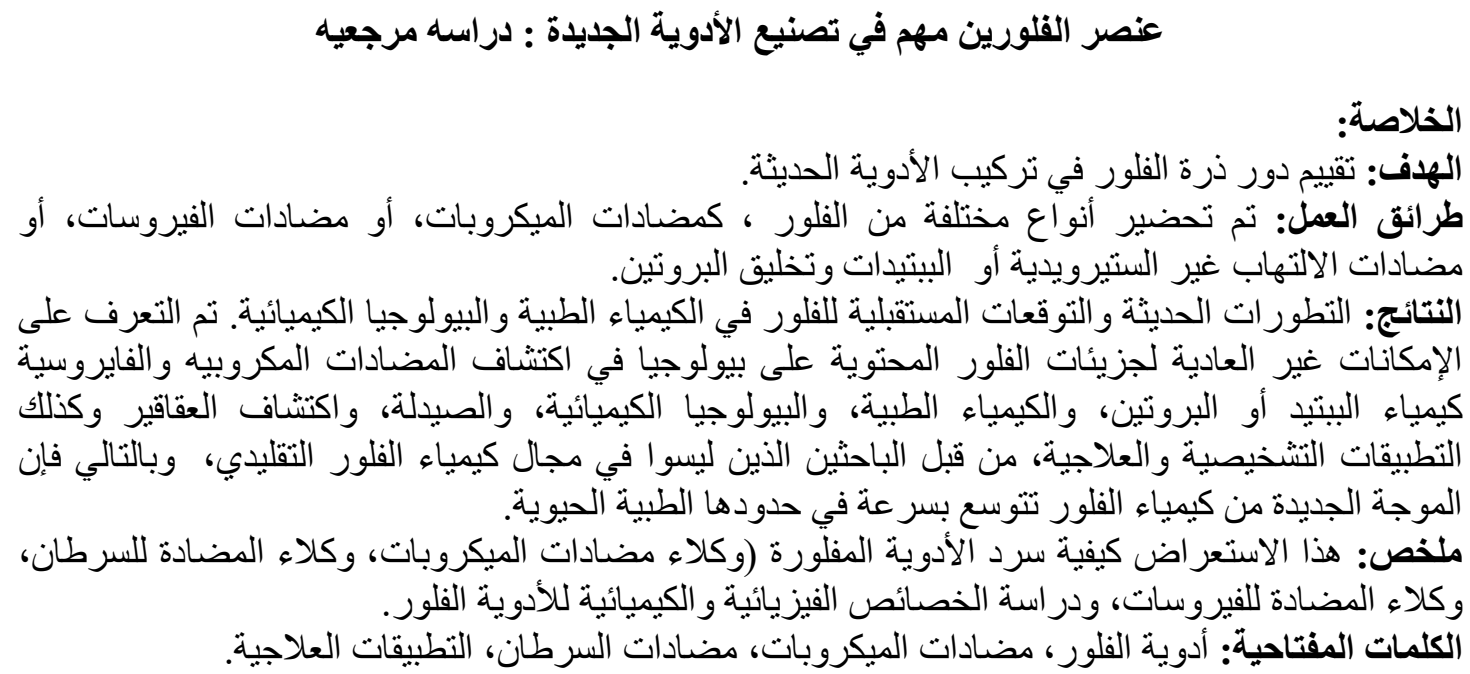

$\mathbf{F}$

luorine is the most electronegative and reactive of all elements in the periodic table. It is active element chemically and biologically due to their specific properties and, with other fluorine

containing functional groups, is a most effective element in biological substances, pharmaceuticals, agrochemicals, liquid crystals, dyes, polymers and a wide range of consumer products ${ }^{1}$. 
Fluorine rarely occurs naturally in biological molecules, and many compounds containing fluorine are toxic. Fluorine is a common element added to pharmaceuticals because it can increase the drug's selectivity, enable it to dissolve in fats, and decrease the speed at which the drug is metabolized, thus allowing it more time to work $^{1,2}$.

The effect has been associated with the conversion of the enamel hydroxyapatite $\mathrm{Ca}_{5}\left(\mathrm{PO}_{4}\right)_{3}(\mathrm{OH})$ to fluorapatite with a reduction in acid solubility ${ }^{3}$ and increase selectivity. It has important effects on the oral bacteria of dental plaque, which are responsible for the acidification of plaque that results in demineralization. Other uses in the isotopic form ${ }^{19} \mathrm{~F}$ in chemistry and ${ }^{18} \mathrm{~F}$ is a commercially important source of positrons. Its major value is in the production the radiopharmaceutical fludeoxygluco se, used in positron emission tomography in medicine ${ }^{4}$.

General properties of Fluorine

Some properties are affecting the drugs:

$1-\mathrm{pKa}$

2- Steric effects

3-Lipophilicity

4-Inductive effect

5- Hydrogen bonding

6-Isoster.

\section{Fluorine antimicrobial drugs}

The history of work on the prevention of bacterial infection can be traced back to the 20th century. New fluoroquinolones classification is a useful tool for physicians to use when empirically prescribing these drugs or evaluating new agents introduced to the market ${ }^{5}$. Drugs in each group are similar in antimicrobial activity. With each successive generation, a significant new group of pathogens is added to the coverage. 
First Generation<smiles>CCn1cc(C(=O)O)c(=O)c2ccc(C)nc21</smiles>

Nalidixic Acid

Third Generation<smiles>CC1COc2c(N3CCN(C)CC3)c(F)cc3c(=O)c(C(=O)O)cn1c23</smiles>

These newer fluoroquinolones have a wider clinical use and a broader spectrum of antibacterial activity including $\mathrm{G}^{(-)}$ve \& $\mathrm{G}^{(+)}$ve aerobic and anaerobic organisms. Some of the newer fluoroquinolones have an important role in the treatment of community-acquired pneumonia and intra-abdominal infection They are primarily used against urinary tract infections and are also clinically useful
Second Generation<smiles>O=C(O)c1cn(C2CC2)c2cc(N3CCNCC3)c(F)cc2c1=O</smiles>

Fourth Generation<smiles>COc1c(N2C[C@H]3CCCN[C@H]3C2)c(F)cc2c(=O)c(C(=O)O)cn(C3CC3)c12</smiles>

against prostatitis, infections of skin and bones and penicillin resistant sexually transmitted diseases ${ }^{5 \& 6}$.

\section{Beta-Lactamase inhibitors}

Novel compounds have activity against $\beta$-lactamase producing strains, it is possible that their molecular target is different than the known targets of the $\beta$-lactams ${ }^{7}$. 


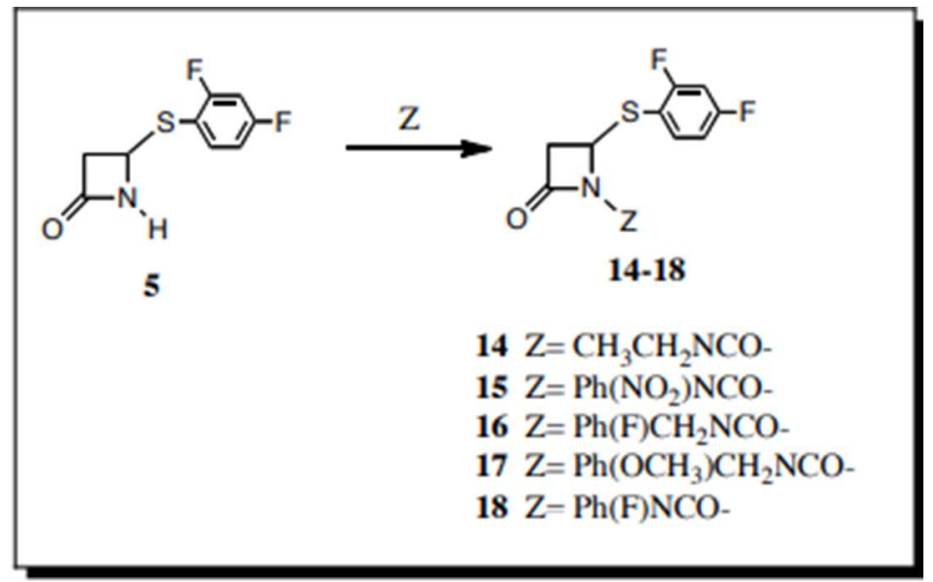

To date, we have synthesized cadres of compounds with demonstrated good activity (minimum inhibitory (MIC) and minimum bactericidal concentration, $\mathrm{MBC}, \quad<15 \mathrm{ug} / \mathrm{ml}$ ) against Mycobacterium tuberculosis (Mtb) or Moraxella catarrhalis (M.cat.).

\section{Fluorine in Anti Fungal agents}

Recently, the World Health Organisation (WHO) and the Infectious Disease Society of America (IDSA) recommended that the first line treatment for $\mathrm{CM}$ is a combination of amphotericin B and Flucytosine, both now WHO Essential Medicines.
Fluconazole as a model of anti fungal agent that containing two fluorine atoms. Chemically, is a triazole antifungal drug.. It can be given orally or intravenously. Other advantages are well tolerated, favorable pharmacokinetic properties, but a narrow therapeutic range.

Voriconazole is a second generation synthetic derivatives of fluconazole by addition of methyl group to the propyl backbone and substitution of triazole moiety with a fluropyrmidine group. Active against yeast and moulds. Fungicidal in vitro against Aspergillus spp and fungistatic in vitro against Candida spp.

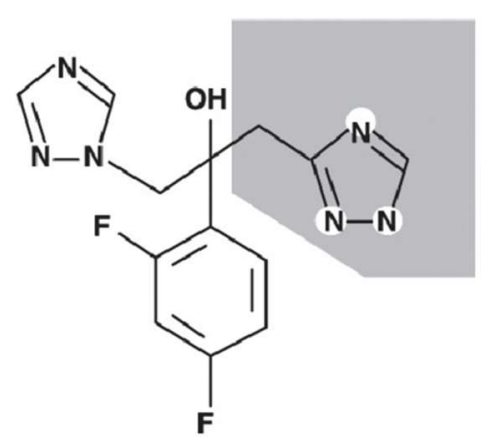

Fluconazole

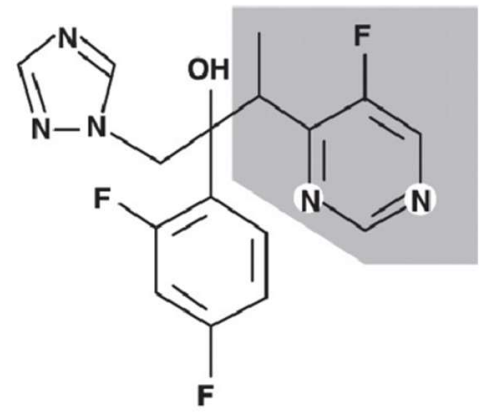

Voriconazole

\section{Fluornate pyrimidine derivatives}

5-Flourouracil [ 5-FU ]; An antimetabolite fluoropyrimidine analog 
of the nucleoside pyrimidine with antineoplastic activity.

It is active against a limited range of systemic fungal infections, being effective mainly in those caused by yeast. It has activity against
Candida spp., C. neoformans and some fungi causing chromoblastomycosis.

Monotherapy now limited, can be used in combination therapy due to restricted spectrum activity ${ }^{7}$.<smiles>Nc1nc(=O)[nH]cc1F</smiles>

5-Fluorocytosine

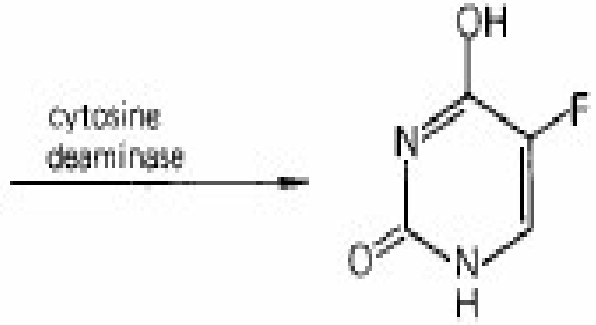

5-Fluorouracil

\section{Anti-viral fluorinated drugs}

The Ledipasvir and sofosbuvir are antiviral medications that prevent hepatitis $\mathrm{C}$ virus (HCV) from multiplying in your body.
It is a combination medicine used to treat chronic hepatitis $\mathrm{C}$ in adults and children who are at least 12 years old or who weigh at least 77 pounds $(35 \quad \text { kilograms })^{8}$.

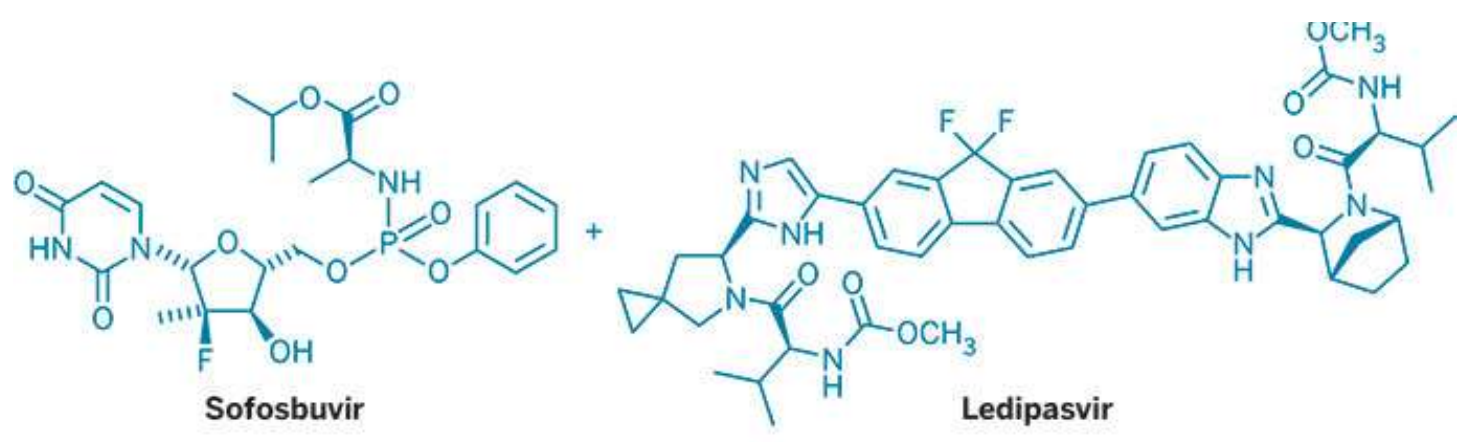

Gilead Sciences' Harvoni

Other medical uses of Fluorinate drugs

Fluoroine play an important role in the steroid skeletondrugs, It is prevents the conversion of testosterone to dihydrotestosterone (DHT) in the body. DHT is involved in the development of benign prostatic hyperplasia $(\mathrm{BPH})^{9}$. 


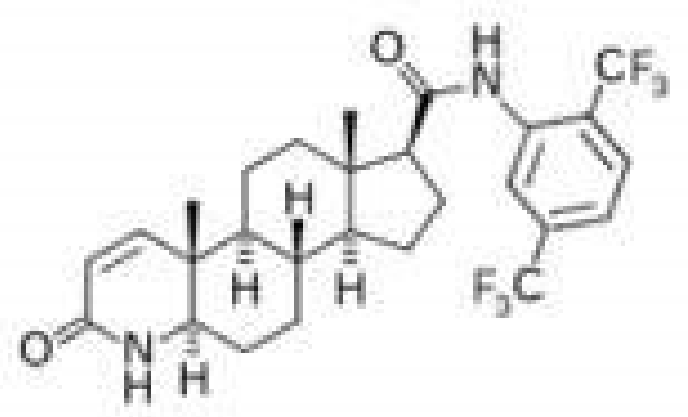

Respiratory system drugs, patients with severe COPD associated Roflumilast ; phosphodiesterase-4 with chronic bronchitis and a history of Enzyme inhibitors Indicated to reduce exacerbations. the risk of COPD exacerbations in

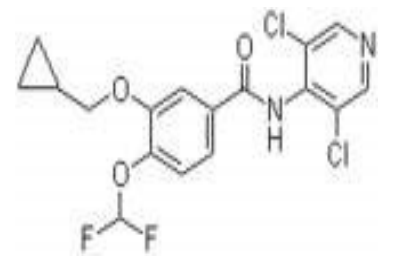

Anti-Diabetes Drugs are another types of fluorinated drugssuch as Sitagliptin; brand name,Januvia ${ }^{\circledR}$ It to lower blood sugar in patients with high blood sugar (diabetes) type II.

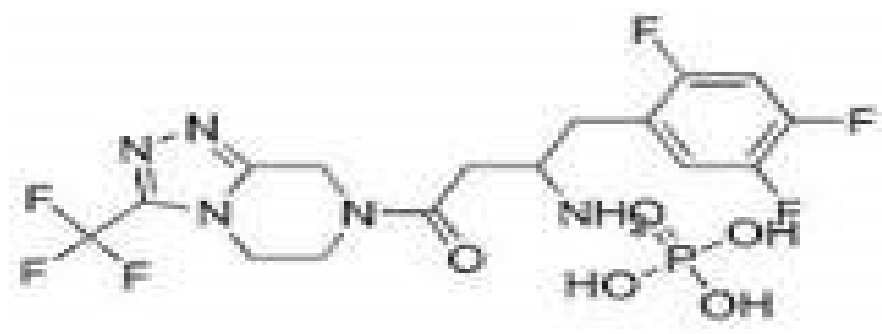

Also, fluorinated non steroidal anti-inflammatory F-NSAIDs as new family such as Celecoxib ${ }^{10}$. 


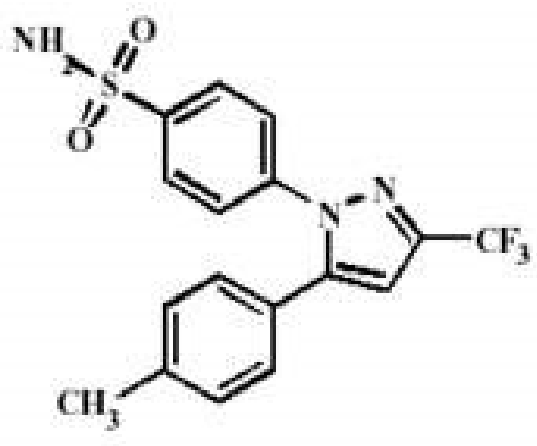

\section{Analytical methods used for determination of $\mathrm{F}$-agents}

Currently, various instrumental analytical methods based on chromatography, spectroscopy, and electrochemistry are used to determine some of these fluorine-containing compounds ${ }^{11}$. techniques such chromatography, HPLC, gas chromatography or capillary electrophoresis, and spectrophotometric Ultraviolet (UV), Nuclear Magmatic Resonance (NMR). Fluorinated gas agent can be used as contrast media in Ultrasound for diagnostic cardiac diseases such as Perflutren $^{11}$. 
<smiles>C[C@H](N[C@@H](CC(C(=O)O)C(F)(F)F)C(=O)O)C(F)(F)F</smiles><smiles>CC(CC(F)(F)F)[C@H]([NH3+])C(=O)O</smiles>
tFlle<smiles>CC(C[C@H]([NH3+])C(=O)[O-])C(=O)[O-]</smiles>
tFLeu

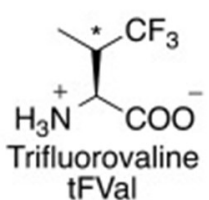
tFVal

\section{Conclusion}

Our conclusion fluorine - containing substituents and functional groups from a medicinal chemistry point of view and then the applications of those characteristics to organic, bioorganic, as well as chemical and biomedical researches.

\section{References}

1- Audi, G.; Kondev, F. G.; Wang, M.; Huang, W. J.; Naimi, S. Chinese Physics C. 2017;41 (3): 030001. doi:10.1088/16741137/41/3/030001.

2- King Lo. Hugh Cornell, Gina Nicoletti, Helmut M Hügel . A Study of Fluorinated $\beta$ Nitrostyrenes as Antimicrobial Agents. Applied Sciences. 2012; 2(4):114-128 . DOI: 10.3390/app2010114.

3- Jiang Wang, María SánchezRoselló, José Luis Aceña. Carlos del Pozo

Alexander E. Sorochinsky., Santos Fustero, Vadim A. Soloshonok ,Hong Liu. Fluorine in Pharmaceutical Industry: FluorineContaining Drugs Introduced to the Market in the Last Decade (20012011). Chem. Rev. 2014; 114, 4, : 2432-2506.

doi.org/10.1021/cr4002879.
4- PyykkO P., Mol. Phys. 2008; 106, :1965-1974.

5- V.L. Tunitskaya, A.R. Khomutov, S.N. Kochetkov, S.K. Kotovskaya, and V.N. Charushin.. Inhibition of DNA Gyrase by Levofloxacin and Related FluorineContaining Heterocyclic Compounds. ActaNaturae.2011; 3(4): 94-99.

6- Eric P. Gillis, Kyle J. Eastman, Matthew D. Hill, David J. Donnelly, Nicholas A. Meanwell.. Applications of Fluorine in Medicinal Chemistry. J. Med. Chem. 2015; 58, 21, :8315-8159.

7- Sanshu Li and Ronald R. Breaker. Fluoride Enhances the Activity of Fungicides that Destabilize Cell Membranes. Bioorg Med Chem Lett. 2015; 22(9), :3317-3322.

8- Cavaliere A, Probst KC , Westwell AD , Slusarczyk M. Fluorinated nucleosides as an important class of anticancer and antiviral agents. Future Med Chem. 2017 Oct;9(15):1809-1833. doi: 10.4155/fmc-2017-0095

9- XiaopingYang, AiyingGuan.. Application of fluorine-containing non-steroidal anti-androgen compounds in treating prostate cancer. J. Fluorine Chem. 2014; 141 : $1-10$. doi.org/10.1016/j.jfluchem.2014.02. 001 . 
10- Fujisawa H, Fujiwara T, Takeuchi Y, Omata K.. Synthesis and optical resolution of 2-aryl-2fluoropropionic acids, fluorinated analogues of non-steroidal antiinflammatory drugs (NSAIDs). Chem Pharm Bull (Tokyo).2005; 53(5): :524-8. DOI:10.1248/cpb.53.524.

11- Vera Paefgen, Dennis Doleschel, and Fabian Kiessling.. Evolution of contrast agents for ultrasound imaging and ultrasound-mediated drug delivery. Front Pharmacol. 2015; 6: 197. doi: 10.3389/fphar.2015.00197.

12-Benjamin C Buer and E Neil G Marsh. Fluorine: A new element in protein design. Protein Sci. 2012 ; Apr; 21(4): 453-462. doi: 10.1002/pro.2030. 